This item was submitted to Loughborough's Research Repository by the author.

Items in Figshare are protected by copyright, with all rights reserved, unless otherwise indicated.

\title{
A multi-body human model for rear-impact simulation
}

PLEASE CITE THE PUBLISHED VERSION

PUBLISHER

(C) Professional Engineering Publishing

VERSION

VoR (Version of Record)

LICENCE

CC BY-NC-ND 4.0

REPOSITORY RECORD

Himmetoglu, Selcuk, Memis Acar, Kaddour Bouazza-Marouf, and Andrew J. Taylor. 2019. "A Multi-body Human Model for Rear-impact Simulation". figshare. https://hdl.handle.net/2134/4526. 
This item was submitted to Loughborough's Institutional Repository (https://dspace.lboro.ac.uk/) by the author and is made available under the following Creative Commons Licence conditions.

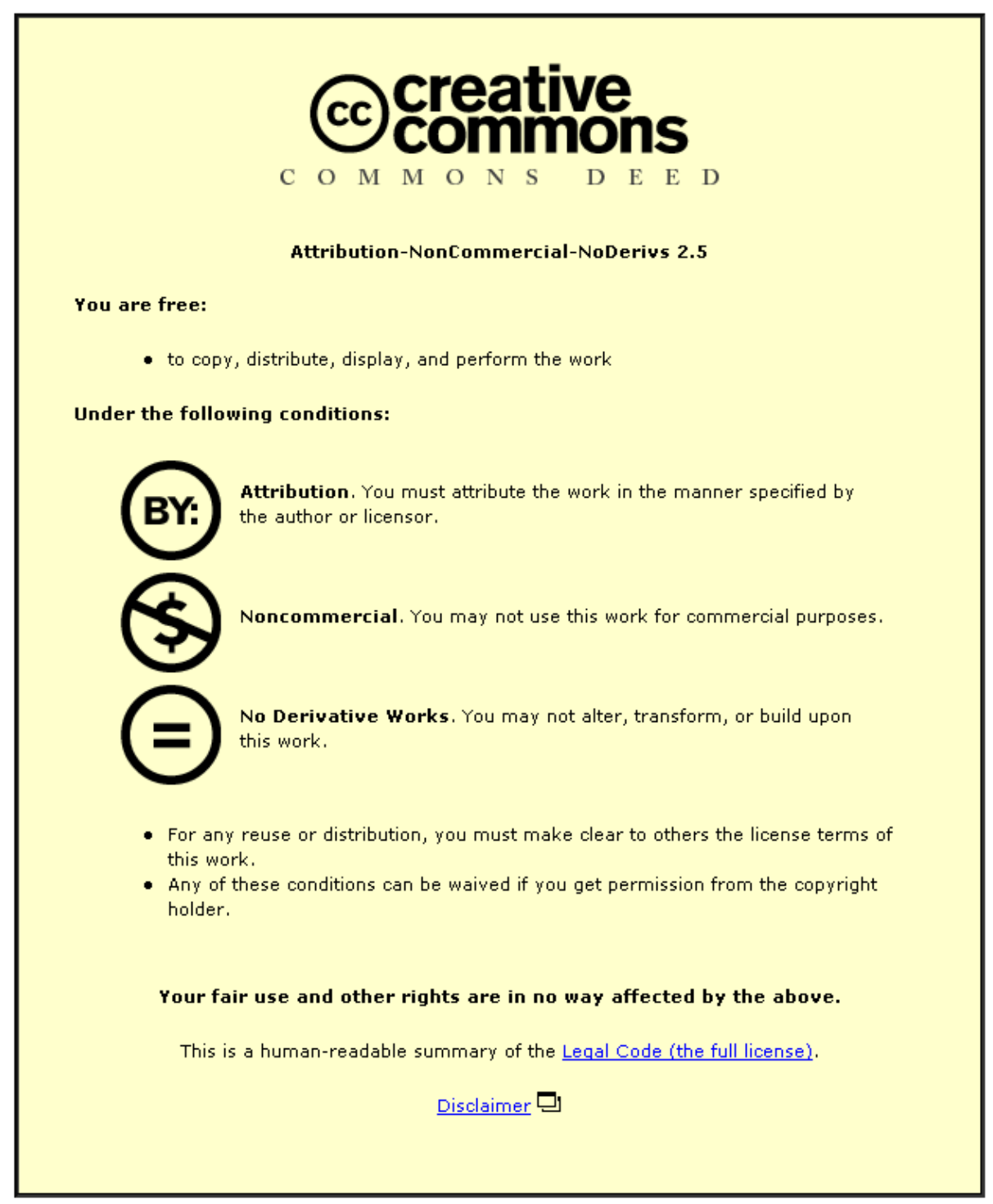

For the full text of this licence, please go to: http://creativecommons.org/licenses/by-nc-nd/2.5/ 


\title{
A multi-body human model for rear-impact simulation
}

S Himmetoglu*, M Acar, K Bouazza-Marouf, and A Taylor

Wolfson School of Mechanical and Manufacturing Engineering, Loughborough University, Loughborough, UK

The manuscript was received on 31 July 2008 and was accepted after revision for publication on 12 January 2009.

DOI: 10.1243/09544070JAUTO985

\begin{abstract}
This paper presents the validation of a 50th-percentile male multi-body human model specifically developed for rear-impact simulation. The aim is to develop a biofidelic model with the simplest architecture that can simulate the interaction of the human body with the seat during rear impact. The model was validated using the head-and-neck and torso responses of seven volunteers from the Japanese Automobile Research Institute sled tests, which were performed at an impact speed of $8 \mathrm{~km} / \mathrm{h}$ with a rigid seat and without head restraint and seat belt. The results indicate that the human-body model can effectively mimic the rear-impact response of a 50th-percentile male with a good level of accuracy and has the potential to predict whiplash injury.
\end{abstract}

Keywords: multi-body human model, whiplash, rear impact, validation

\section{INTRODUCTION}

Whiplash is a neck injury caused by the sudden differential movement between the head and torso. It has been found that rear-end collisions in car accidents pose a high risk of sustaining whiplash [1, 2]. Whiplash can lead to long-term disablement and discomfort associated with substantial economical cost which has been estimated to be $£ 1.2$ billion in the UK [1] and US $\$ 8.2$ billion in the USA [3] annually.

Biofidelic human-body models are invaluable tools in evaluating car seat designs for rear-impact whiplash mitigation and in predicting injury. In comparison with finite element models, multi-body human models are computationally efficient tools and capable of predicting successfully the global responses of the human body under impact loading [4]; hence they can enable the designer to shorten the development and optimization of car seat models and other safety systems. However, there is a lack of complete and reliable data on the mechanical properties of the human body due to the difficulties involved in the full characterization of

*Corresponding author: Wolfson School of Mechanical and, Manufacturing Engineering, Loughborough University, Loughborough, LE11 3TU, UK. email: s.himmetoglu@ymail.com; zelchuk@hotmail.com the constitutive behaviour of individual soft tissues such as ligaments, muscles, and intervertebral disks. Although tissue mechanical properties are highly complex and strain rate dependent, the rate behaviour is not fully established since the current experimental facilities are not fully capable of identifying the properties at the high strain rates that occur during impact. The reported mechanical properties vary considerably, depending on the test and specimen-preserving conditions, the post-mortem time, and the age and gender of the cadaveric specimens [5]. Also, human response to impact is controlled by complex neural feedback mechanisms which can involve voluntary and reflex muscle contractions, and such mechanisms are still not completely understood [6].

In spite of these difficulties, volunteer and cadaver impact test data and the reported soft tissue properties are the only available sources that can be used for the validation of human body models. Multibody human models $[4,7]$ are effective tools in this respect since they have fewer number of parameters than finite element models do [8]; hence, when new and complete biomechanical data become available, the properties of the model can be more readily updated and rectified. Therefore, the main focus of this study is to develop a biofidelic multi-body human $(\mathrm{BMH})$ model with the lowest complexity which can be economically used to evaluate the 
protection offered by car seat designs under rearimpact conditions. The proposed multi-body human model studied in this paper is the BMH model.

\section{BACKGROUND}

\subsection{Rear-impact multi-body human models}

The most prominent multi-body human models specifically designed for rear impact are presented in this section. Jakobsson et al. [9] built a twodimensional multi-body human model using MADYMO in which the spine consisted of 24 vertebral bodies connected by one-degree-of-freedom rotational joints. The time dependence of the muscle reflexes was not considered and the validation of this model included only qualitative comparisons made for a single-impact severity with $\Delta V=7.83 \mathrm{~km} / \mathrm{h}$.

van den Kroonenberg et al. [10] developed a rearimpact multi-body human model by modifying the entire spine of a 50th-percentile male Hybrid III MADYMO model. This model formed the basis of the TNO multi-body human model. The modified spine was composed of 24 vertebral bodies. The thoracic and lumbar spine model and the posture were based on the anthropometry of a 50th-percentile male in a typical driving posture $[\mathbf{1 1}]$. The spine model was built as a three-dimensional model, but only two degrees of freedom (flexion-extension and axial elongation-compression) were allowed between each vertebral body. Linear stiffness and damping properties were used for each spine joint. The mechanical properties of these joints represented the equivalent resistance of the local soft tissues and surrounding muscles at each spine joint. The model was subjected to three different crash severities (at $\Delta V=5.7 \mathrm{~km} / \mathrm{h}, 20 \mathrm{~km} / \mathrm{h}$, and $30 \mathrm{~km} / \mathrm{h}$ ) using a seat model with and without a head restraint. However, the validation of the model was incomplete because of a lack of experimental data available at the time.

Eriksson [12] built a multi-body model of the mechanical biofidelic rear-impact dummy I (BioRID I) [13] in MADYMO. The computational model did not have the muscle substitute cables of the mechanical counterpart, but their effect was integrated into the mechanical properties of the cervical spine joints. Rear-impact sled tests at $\Delta V=17 \mathrm{~km} / \mathrm{h}$ were conducted using the mechanical BioRID I and four different car seats. The computational model was then subjected to the same impact conditions using the validated models of the car seats. The behaviour of the computational BioRID I was not found to be satisfactory for some of the responses, especially the accelerations of the first thoracic vertebra (T1).

Using experimental modal analysis, Willinger et al. [14] represented the human head-and-neck by a two-degrees-of-freedom system and identified its mechanical properties. Following this, Bourdet and Willinger [15] developed a lumped-parameter multibody human torso model using the experimental results of Kitazaki and Griffin [16], which had been obtained by subjecting eight healthy male volunteers, aged between 20 and 35 years old (height, $1.78 \pm 0.07 \mathrm{~m}$, mass, $74.6 \pm 7.8 \mathrm{~kg}$ ), to vertical random vibrations while adopting erect, normal, and slouched sitting postures on a rigid seat without a seat back. Using modal analysis techniques, a torso model consisting of five rotational joints of one degree of freedom was developed. The torso joints were placed approximately at the anatomical locations of T1, T6, T12, L3, and S2. The segments of the human-body model were defined as rigid bodies. The stiffness and damping properties of the torso joints were linear and they were determined through validation against the results of Kitazaki and Griffin [16]. The torso model was able to capture the first five experimental vibration modes in terms of natural frequencies, damping, and mode shapes. Using a finite element model of a typical car seat, the human-body model was subjected to a rear-impact pulse with a $\Delta V=16 \mathrm{~km} / \mathrm{h}$ and its dynamic behaviour was compared with that of a completely rigid torso. However, the developed model was not validated against the published volunteer responses in rear-impact experiments.

\subsection{Validation data for rear-impact human-body models}

The number of whole-body cadaver and volunteer rear-impact experiments is quite limited in the literature. Also, detailed information about the experimental conditions and the complete set of responses required for validation are not recorded or well documented [4]. The data from the Japanese Automobile Research Institute (JARI) rigid-seat volunteer sled tests conducted by Davidsson et al. [17] and Ono et al. [18] are the most comprehensive published data that can be used to validate the rearimpact response of human-body models. These sled tests were conducted with seven healthy 50thpercentile male volunteers ( $25 \pm 4$ years of age) without head restraint and seat belt. In these tests, a rigid wooden seat mounted on a sled was allowed to slide on a long rail to engage an oil damper at the 
end at an impact speed of $8 \mathrm{~km} / \mathrm{h}$. As a result of the impact, the sled attained $\Delta V=9.3 \mathrm{~km} / \mathrm{h}$ with mean and peak accelerations of $1.8 \mathrm{~g}$ and $3.8 \mathrm{~g}$ respectively. The validation of a multi-body head-and-neck model using the JARI rigid-seat sled test data has been presented by Himmetoglu et al. [4] together with some detailed information about the JARI test method.

Ono et al. [18] presented the only experimental data in the literature that can be utilized to validate the rear-impact deformation of the thoracic and lumbar spines by seat loading. In these experiments [18], the same group of volunteers used in the study by Davidsson et al. [17] were subjected to the JARI rear-impact rigid-seat sled tests as described above. A tape sensor was adhered to the skin over the spine to record the rotations of each vertebra. Ono et al. [18] provided the vertebra rotations of one representative volunteer in which the initial angle was set to zero for each vertebra, as shown in Fig. 1. These data were utilized to validate the torso responses of the BMH model.

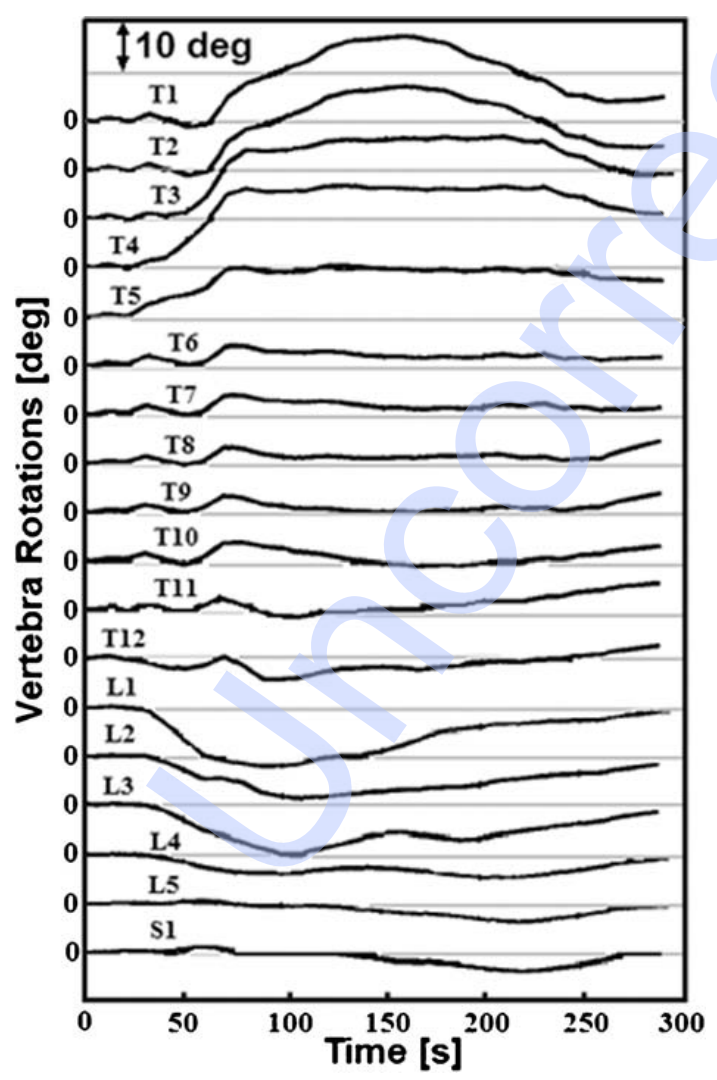

Fig. 1 Changes in vertebra rotations (adapted from reference [18])

\section{DEVELOPMENT OF THE BMH MODEL}

\subsection{Geometrical and inertial properties of the BMH model}

The BMH model is designed to work only in the sagittal planes since the validation data in the literature pertain to non-oblique rear impacts in which the occupant body segments are ideally forced to move in a symmetrical fashion with respect to the midsagittal plane (the median plane extending in the fore-aft direction, dividing the human body into right and left parts equally). The contour of the $\mathrm{BMH}$ model is based on the research by the University of Michigan Transportation Research Institute (UMTRI) [11] and it represents the typical or normal driving posture of an average 50thpercentile male as depicted in Fig. 2. In defining the normal driving posture, the human subjects were seated in a typical seat with a fixed seat-back angle which produced a torso back angle of $25^{\circ}$ approximately from the vertical. The subjects were then told to sit upright, with their back pressed against the seat back and the head looking forwards.

The joint centres of the BMH torso model is determined using the vertebra rotations (Fig. 1) obtained from the spinal deformation experiments [18]. The vertebrae which approximately rotate together as a unit are grouped as one separate rigid body. For each time interval of $50 \mathrm{~ms}$, a sufficient number of torso joints was identified to describe approximately the relative motions within the torso. Then, a final set of torso joints was selected that can account for the whole time interval (i.e. from $0 \mathrm{~ms}$ to $300 \mathrm{~ms}$ ). This final set of joints are placed approximately at the anatomical locations of T3, T5, T11T12 (between T11 and T12), and L3-L4 (between L3 and L4). Hence, the torso segments of the BMH model (Fig. 3(a)) are modelled as rigid bodies and defined as TS1 (which includes T1 to T3), TS2 (which includes T3 to T5), TS3 (which includes T5 to T11), TS4 (which includes T12 to L3), and TS5 (which includes L4 to S1). As shown in Fig. 2, the centres of these four torso joints of the BMH model are placed on the vertebral column lines of the UMTRI body situated on the midsagittal plane. These vertebral column lines were constructed by connecting the approximate centres of rotation of C7-T1, T4-T5, T8-T9, T12-L1, and L5-S1 vertebra pairs only [11]. Therefore, in the BMH model, the exact positions of the torso-joint centres are located using the spine models described by van den Kroonenberg et al. [10]

3 and Jernström et al. [19] which were also based on the UMTRI-body contour. Figure 2 indicates that the 


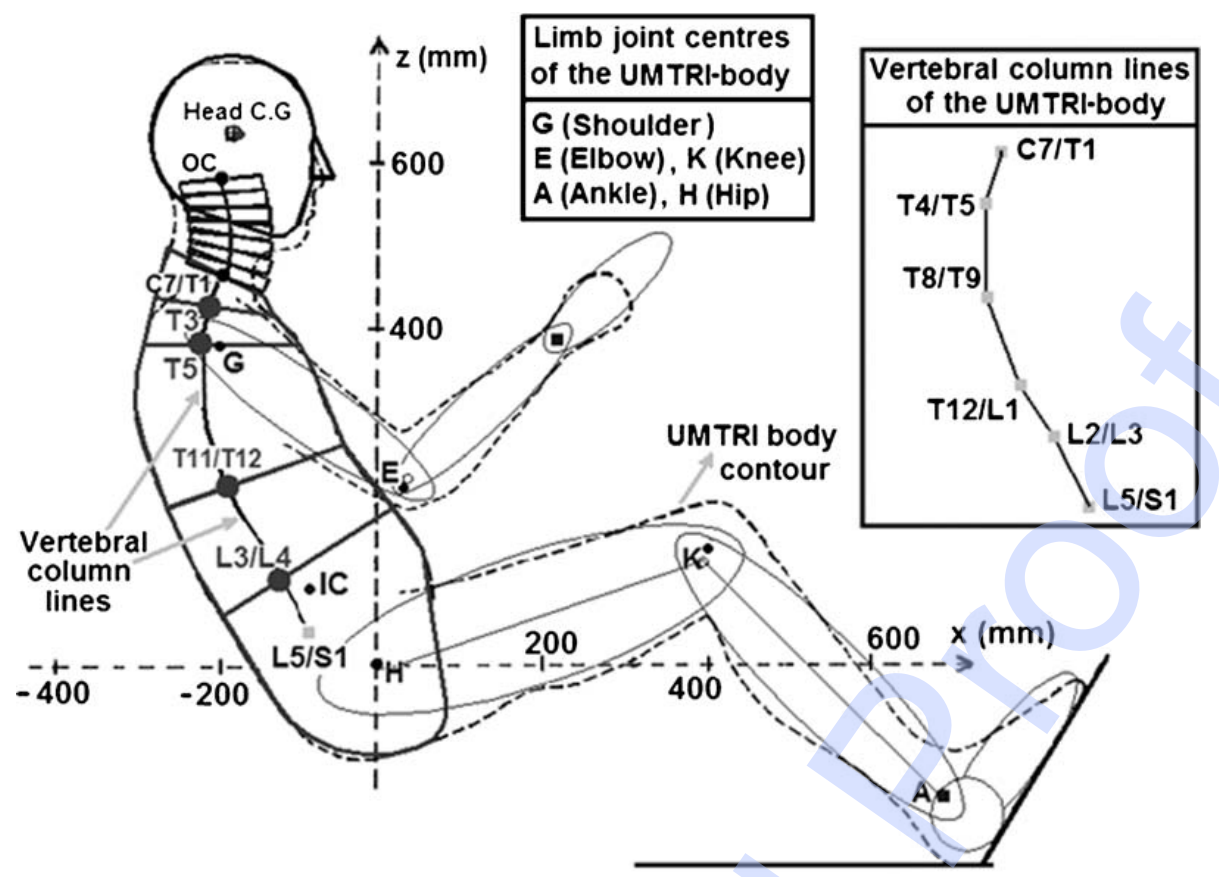

Fig. 2 The BMH model superimposed on the UMTRI-body contour (adapted from reference [11])

positions of all the BMH model joints are in agreement with that of the UMTRI body, which were estimated by using cadaver dissection and radiographic analysis of torso movement [11].

Similar to the BioRID dummy [13], the torso joints of the BMH model allow one degree of rotational freedom between adjacent body segments. As in all the other rear-impact multi-body human models in the literature $[\mathbf{9}, \mathbf{1 0}, \mathbf{1 2 - 1 7}, \mathbf{1 9}]$, defining only rotational freedom for the joints of the whole spine can be considered to be an acceptable approximation to predict the overall motion of the human body in the sagittal plane. Also, it does not seem to be feasible at this stage to derive and justify the use of

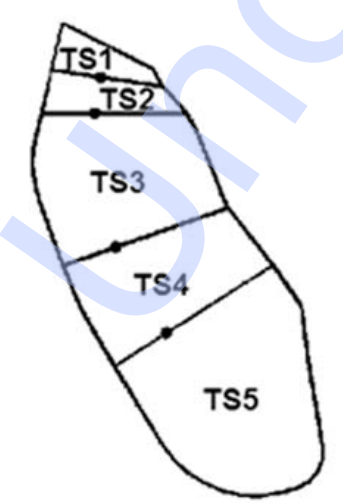

(a)

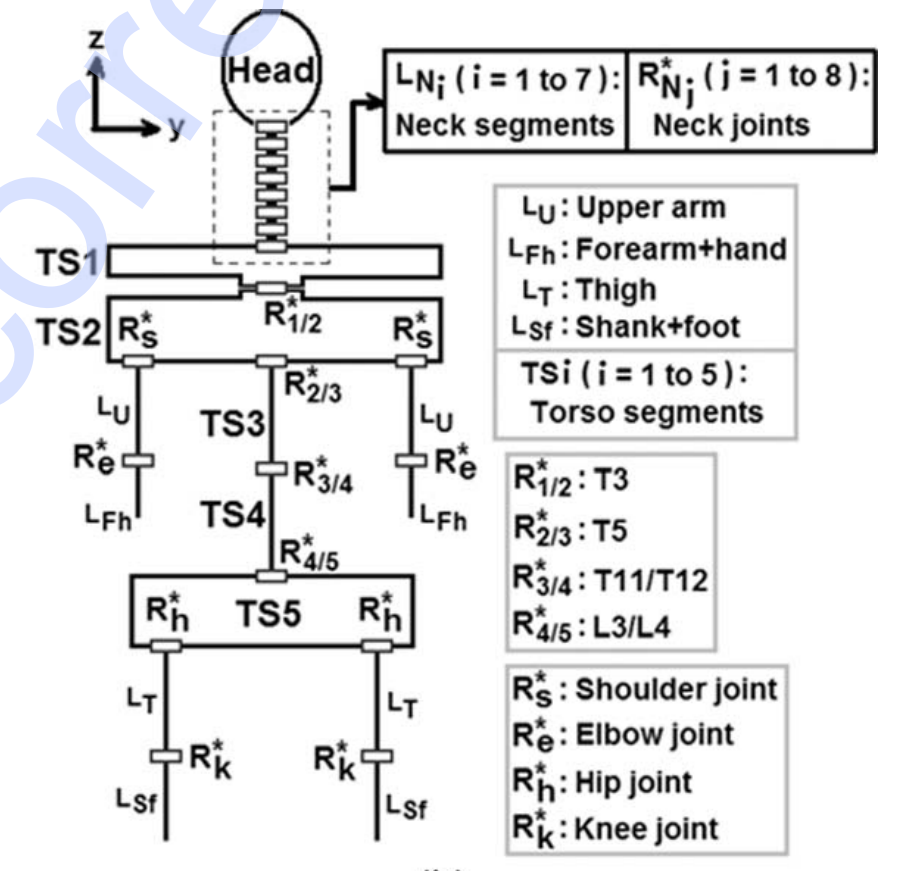

(b)

Fig. 3 (a) The torso segments; (b) the kinematic structure of the BMH model 
translational stiffness and damping properties of the joints of the BMH model owing to limited validation data. Even in the spinal deformation experiments by Ono et al. [18], no numerical data on the translations of the vertebrae and pelvis relative to the rigid seat were provided. In their multi-body human model, van den Kroonenberg et al. [10] integrated axial translational freedom between adjacent vertebrae and defined axial stiffness and damping properties based on the experimental studies carried out in the mid-1970s. However, the results indicated that the rotations at the spine joints were the main mechanism for T1 motion in comparison with the axial displacements, even at a high-severity impact with $\Delta V=30 \mathrm{~km} / \mathrm{h}$.

Figure 2 shows the head-and-neck model given by Himmetoglu et al. [4] integrated into the BMH torso model. It can be seen that the initial configuration and the geometry of the head-and-neck model (including the locations of occipital condyles (OCs), C7-T1, and head centre of gravity (CG)) match that of the UMTRI body. The vertebrae orientations and the neck curvature of the head-and-neck model are similar to those of the BioRID dummy, but the novelty of this model lies in the mechanical properties of the intervertebral joints. Figure 2 also shows the limbs of the BMH model superimposed on that of the UMTRI body. In the BMH model, the hands and feet are fixed to the forearms and shanks respectively as they do not play a significant role in rear impact. The geometrical properties of the limbs were obtained from the work of Chaffin and Andersson [20]. The left and right hip and shoulder joints are situated $82 \mathrm{~mm}$ and $173 \mathrm{~mm}$ apart from the midsagittal plane respectively $[\mathbf{1 1}]$. In the JARI rear-impact rigid-seat sled tests [17], iliac crest motion was tracked to quantify the pelvis motion. However, the exact location of the iliac crest skin film target was not reported. Therefore, the iliocristale (IC) which is the most lateral and superior aspect of the iliac crest is chosen to represent the iliac crest motion. The location of IC in the BMH model is as defined in the UMTRI body [11].

An overview of the kinematic structure of the BMH model is depicted in Fig. 3(b), in which the joints and the links are denoted by $\mathrm{R}^{*}$ and $\mathrm{L}$ respectively. The BMH model is composed of rigid bodies connected by one-degree-of-freedom rotational joints $R^{*}$. The joint axes (i.e. the direction along which the rotational freedom is allowed) are in the $y$ direction for all connections between adjacent bodies. This allows the joints to accommodate a rotational spring and a rotational damper which can be connected in parallel.
The inertial properties of the limbs of the BMH model were obtained from the work of Chaffin and Andersson [20]. The masses of the five torso segments were estimated using the mass distribution of the computational BioRID I model [12] and the human-body torso segment mass data given by Chaffin and Andersson [20]. Since there is limited information on the inertial properties of the human torso [20-22], the moments of inertia of the five torso segments were estimated by distributing the mass of each torso segment over the volume of the segment using a homogeneous density assumption. Although the density varies within a body segment, this is regarded as a reasonable approximation in estimating the inertial properties of human-body segments [21-23]. The mass distribution of the BMH model is presented in Table 1 for a 50th-percentile male, i.e. a midsized male in terms of stature and weight.

\subsection{Range of motion of the torso joints of the BMH model}

The range of motion (ROM) of each torso joint of the BMH model is based on literature data. Ono et al. [18] reported the data given in Table 2, on the combined flexion-extension intervertebral ROMs for in-vivo sagittal rotations between adjacent thoracic and lumbar vertebrae. Table 2 indicates a large variation in ROMs for a wide range of population, therefore the mean or representative values should be considered for a 50th-percentile male humanbody model design. In the BioRID design, Davidsson et al. [13] determined the ROMs of the spine joints by utilizing the literature data for the standing posture since there is a lack of reliable ROM data applicable for the typical driving posture. All the BioRID thoracic spine joints were designed to have $3^{\circ}$ of flexion and $3^{\circ}$ of extension ROM but, in the

Table 1 The BMH model segment mass data

\begin{tabular}{lc}
\hline Model Segment & Mass (kg) \\
\hline Head & 4.6 \\
Neck & 1.63 \\
TS1 & 2.6 \\
TS2 & 2.3 \\
TS3 & 10.2 \\
TS4 & 8.365 \\
TS5 & 13.08 \\
Upper arm & 2 \\
Forearm & 1.22 \\
Hand & 0.47 \\
Thigh & 7.4 \\
Shank & 3.11 \\
Foot + Shoe & 1.5 \\
Total mass of BMH model & 74.175 \\
\hline
\end{tabular}


Table 2 The variation in the combined flexionextension ROMs for in-vivo sagittal rotations of the human thoracic and lumbar vertebrae [18]. Representative values are given in parentheses

\begin{tabular}{lc}
\hline Vertebrae & $\begin{array}{l}\text { Combined flexion-extension ROM } \\
\text { (deg) }\end{array}$ \\
\hline T1-T2 & $3-5(4)$ \\
T2-T3 & $3-5(4)$ \\
T3-T4 & $2-5(4)$ \\
T4-T5 & $3-5(4)$ \\
T5-T6 & $2-7(4)$ \\
T6-T7 & $3-8(5)$ \\
T7-T8 & $3-8(6)$ \\
T8-T9 & $3-8(6)$ \\
T9-T10 & $3-8(6)$ \\
T10-T11 & $4-14(9)$ \\
T11-T12 & $6-20(12)$ \\
T12-L1 & $6-20(12)$ \\
L1-L2 & $5-16(12)$ \\
L2-L3 & $8-18(14)$ \\
L3-L4 & $6-17(15)$ \\
L4-L5 & $9-21(16)$ \\
L5-S1 & $10-24(17)$ \\
\hline
\end{tabular}

human spine, the ROMs for the lower thoracic vertebrae are higher than those of the upper thoracic vertebrae, as shown in Table 2. Similarly, all the BioRID lumbar spine joints were designed to have $5^{\circ}$ of flexion and $10^{\circ}$ of extension ROM.

In the $\mathrm{BMH}$ model, since the vertebrae are grouped into five torso segments, an equivalent
ROM is determined for each of the four torso joints using the following procedure, which is also depicted in Fig. 4. For example, in determining the equivalent flexion ROM of the torso joint T11-T12 of the BMH model, the vertebrae (T12, L1, L2, and L3) that are encompassed by the torso segment TS4, are rotated counterclockwise by allowing maximal counterclockwise joint rotations at the corresponding human spine joints (T11-T12, T12-L1, L1-L2, and L2-L3). These maximal joint rotations correspond to the flexion ROMs of the human spine joints within the torso segment TS4. The same procedure is applied to calculate the equivalent extension ROM of the torso joint T11-T12 of the BMH model. The flexion and extension ROMs for each of the human spine joints within the torso segment TS4 (i.e. T11T12, T12-L1, L1-L2, and L2-L3) are selected to be $5.5^{\circ}$ and $9.5^{\circ}$ respectively. This corresponds to a combined ROM of $15^{\circ}$ for each of these human spine joints and this is in accordance with the BioRID lumbar spine joint ROM. The locations of the intermediate human spine joints (T12-L1, L1-L2, and L2-L3) within the torso segment TS4 are estimated using the spine models reported by van den Kroonenberg et al. [10] and Jernström et al. [19].

As TS4 is a rigid body, it cannot deform; hence the line drawn between the torso joints T11-T12 and

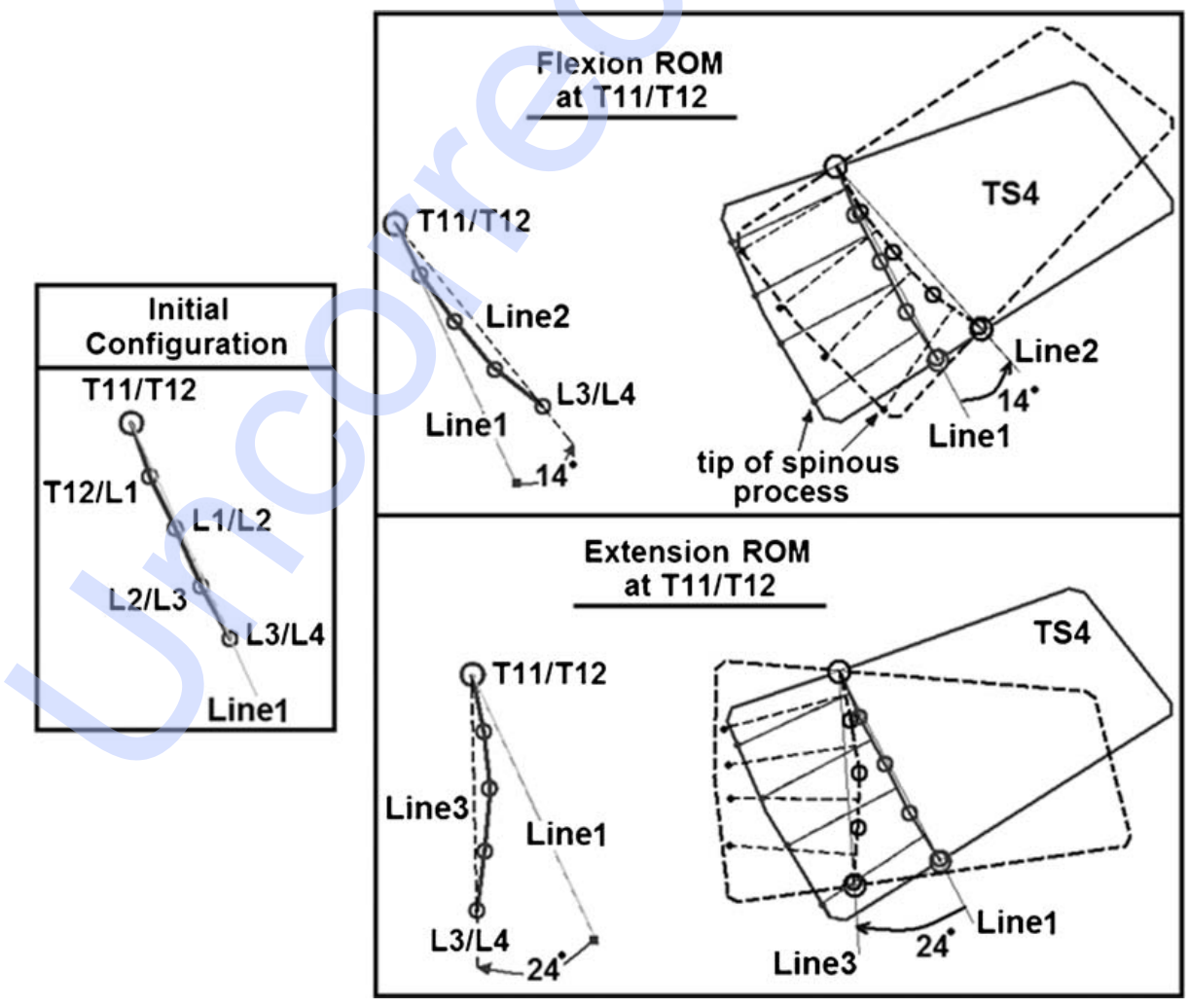

Fig. 4 Equivalent flexion-extension ROMs for the torso joint T11-T12 of the BMH model 
L3-L4 of the BMH model remains always fixed in TS4. In Fig. 4, line 1 indicates the line connecting the torso joints T11-T12 and L3-L4 of the BMH model in its initial configuration. As the human vertebrae (T12, L1, L2, and L3) rotate counterclockwise, line 1 transforms into line 2. Thus, the position vector drawn from T11-T12 to L3-L4 along line 2 indicates the new position of $\mathrm{L} 3-\mathrm{L} 4$ relative to T11-T12 in the BMH model. The deformation of the human spine and the corresponding change in the shape of the human back between the human spine joints T11T12 and L3-L4 can therefore be approximated by the rigid body rotation of TS4 as defined by the rotation of line 1 into line 2 for the flexion motion. Similarly, the rigid-body rotation of TS4, as defined by the rotation of line 1 into line 3 , approximates the extension motion. As shown in Fig. 4, for both the flexion and the extension motions, the initial and the final configurations of TS4 are drawn by the solid and the dashed lines respectively. Consequently, the equivalent flexion and extension ROMs for the torso joint T11-T12 of the BMH model become $14^{\circ}$ and $24^{\circ}$ respectively. Hence, the torso segments, which represent the vertebrae that rotate in a similar fashion under seat-back loading, can still approximate the change in the shape of the human back even when the intervertebral rotations are stretched to their limits.

The equivalent ROMs for the torso joints T3, T5, and L3-L4 of the BMH model are determined in the same manner. For each of the human thoracic spine joints encompassed by TS1 and TS2, the flexion and extension ROMs are both selected to be $3^{\circ}$ which makes the combined ROM slightly higher than the representative values given in Table 2. However, this selection agrees with the BioRID thoracic spine joint ROMs. Also, a slightly higher ROM can be considered to represent the young healthy 50 th-percentile males better in the JARI sled tests. In determining the equivalent ROM for the torso joint L3-L4 of the BMH model, the flexion and extension ROMs for each of the human spine joints encompassed by TS5 are chosen to be $6^{\circ}$ and $10^{\circ}$ respectively since the combined ROMs for the human lumbar spine joints are higher for the lower lumbar spine. Table 3 presents the equivalent ROMs for the torso joints of the BMH model.

\subsection{Mechanical properties and validation of the BMH model}

The mechanical properties of the BMH model relate to the resistances of the joints between adjacent
Table 3 The equivalent ROMs for the torso joints of the BMH model

\begin{tabular}{lcc}
\hline & \multicolumn{2}{c}{ Equivalent ROM (deg) } \\
\cline { 2 - 3 } Torso joint & Flexion & Extension \\
\hline T3 & 4.3 & 4.3 \\
T5 & 4 & 4 \\
T11-T12 & 14 & 24 \\
L3-L4 & 10 & 16 \\
\hline
\end{tabular}

body segments. However, in contrast with head-andneck modelling [4], there is a lack of complete data that can be used to validate the rear-impact motion of both the limbs and the torso segments in relation to the associated muscle activities. In the only comprehensive work reported by Kingma et al. [6], initially relaxed and unaware volunteers were subjected to rear-impact sled tests while the surface electromyography (EMG) of 11 different muscle groups throughout the body were recorded. It was found that the volunteers contracted all of the muscles simultaneously, including those at the chest, legs, and arms with considerable contraction amplitudes. This indicates that, in addition to the neck muscles, the motion of the torso is influenced by the contraction of the muscles inside the torso and the limbs. However, like many other studies in the literature, Kingma et al. [6] presented the responses of the head and upper torso only.

It is common practice in human-body modelling to combine data from different sources $[\mathbf{4}, \mathbf{5}, \mathbf{2 3}]$ since there are limited data on the mechanical properties of human-body segments. Considering these limitations, the mechanical properties of the four torso joints of the BMH model are determined through validation against volunteer response data. During this process, the overall effects of torso and limb muscle contraction are lumped to the four torso joints. For the joints associated with the limbs (shoulder, elbow, hip, and knee joints), passive resistance (i.e. the restraining effect of the soft tissues without any voluntary or reflex muscle contraction) is considered. There are also other approximations involved in human-body modelling. For instance, lumped-parameter models, such as the BMH model, do not incorporate the extension and compression of soft tissues and the associated volume changes within the abdomen and lower thorax when the torso segments rotate relative to each other. However, determining the mechanical properties of joints through validation can also compensate for such approximations.

Joint passive resistance properties of human limbs pertaining to midsized healthy males are well 
established in the literature. The shoulder-joint, hipjoint and elbow-joint passive stiffness functions of the $\mathrm{BMH}$ model are obtained from the work of Robbins [21, 22], whereas the corresponding passive damping functions are derived from the studies by Engin [24], Tafazzoli and Lamontagne [25] and Hayes and Hatze [26] respectively. The knee-joint passive stiffness and damping functions are based on the studies of Robbins $[\mathbf{2 1}, \mathbf{2 2}]$ and McFaull and Lamontagne [27].

The BMH model was validated against the JARI rigid-seat volunteer responses $[17,18]$. First, a previously validated multi-body head-and-neck model by Himmetoglu et al. [4] was integrated into the BMH torso model, and then the whole body was subjected to the JARI impact conditions. As shown in Fig. 5, the initial posture of the BMH model suiting that of the JARI volunteers was determined from the volunteer photographs taken prior to impact. The limb angles, seat, and sled dimensions were taken from reference [28]. The volunteer posture differed from that of the UMTRI-body geometry; therefore TS4 is rotated clockwise by $2^{\circ}$ relative to TS3 and, similarly, TS5 is rotated clockwise by $2^{\circ}$ relative to TS4.

The segments of the BMH model, the seat, and the sled are modelled as rigid bodies using MSC VisualNastran 4D-2001 multi-body dynamics simulation software. The contacts between rigid bodies can be manipulated by the default contact model of VisualNastran [29] in which the programme calculates the forces and impulses to prevent interpenetration of rigid bodies when they are selected by the user to collide with each other. However, in the default contact model of VisualNastran, the user does not have much control, other than entering single values of restitution and friction coefficients. Therefore, a contact model was developed specifically for the torso segments to replace that of

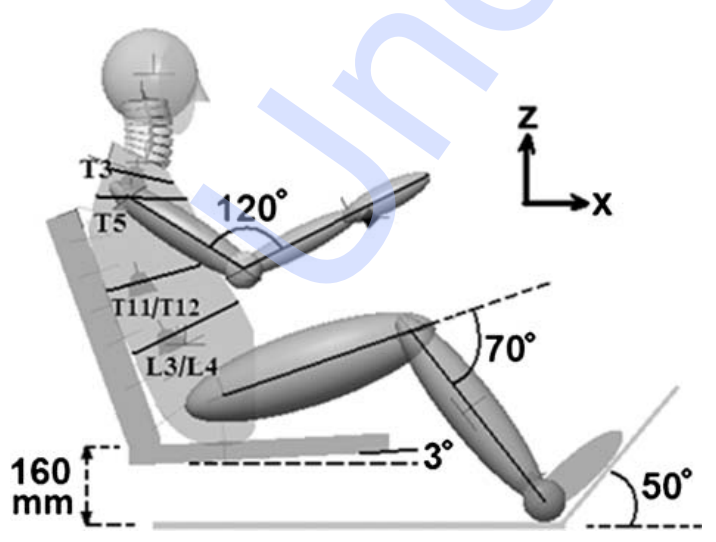

Fig. 5 The seating posture of the BMH model
VisualNastran. The developed contact model allows interpenetration of rigid bodies and it was formulated using MATLAB/Simulink integration in VisualNastran. Considering that the rigid seat was covered with a special mat covered with pressure sensors in the JARI sled tests, the developed contact model is also capable of simulating the compliancy of the human back, the buttocks, and the mat. Thus, a sufficient number of rectangular contact surfaces (S1 to S8) which follow the geometry of the human back are defined on the torso segments, as shown in Fig. 6 . As the human body contacts the rigid seat, the human back conforms to the planar rigid surfaces, therefore using rectangular contact surfaces should be a good approximation. The breadth of the contact surfaces (i.e. the width of the rectangles when viewed in the $y-z$ plane of the inertial coordinate system shown in Fig. 6) were estimated from the measurements taken on the subjects in the UMTRI study [11]. The breadth of the contact surfaces on TS3, TS4, and TS5 are $350 \mathrm{~mm}, 325 \mathrm{~mm}$, and $350 \mathrm{~mm}$ respectively. The interaction of the limbs with the seat surfaces are handled by the built-in contact models of VisualNastran.

In order to define the normal forces applied by the rigid surfaces on the torso segments, the experiments of Viano et al. [30] were utilized in which unembalmed cadavers were impacted by a pendulum at the back just below T1 and T6. Utilizing the impact force versus penetration characteristics obtained from these tests, the function given in Fig. 7 was constructed through $\mathrm{BMH}$ model response validation together with the torso-joint mechanical properties. The function describes the pressure developed as the BMH model contact surfaces

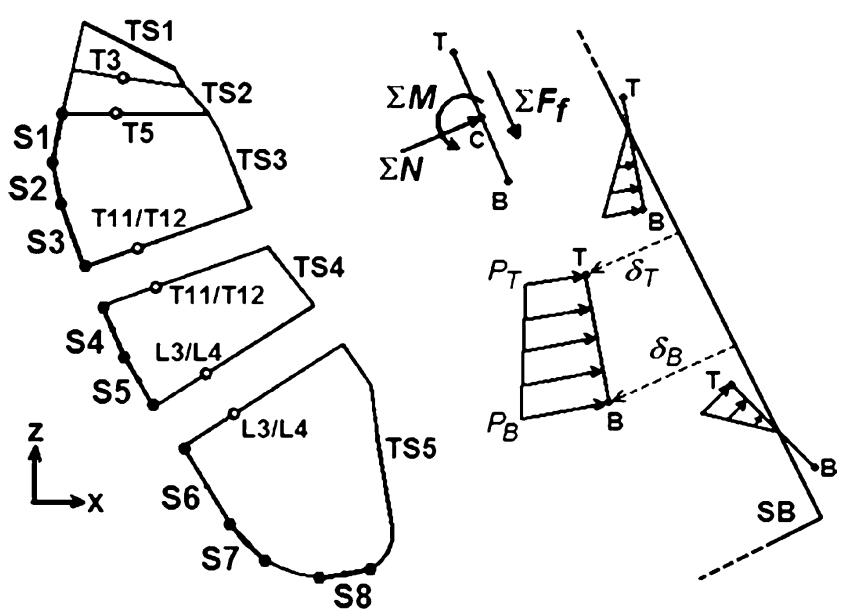

Fig. 6 Definition of the contact surfaces and forces (SB, Seat back; T, Top edge; B. bottom edge; C. geometrical centre of each contact surface) 


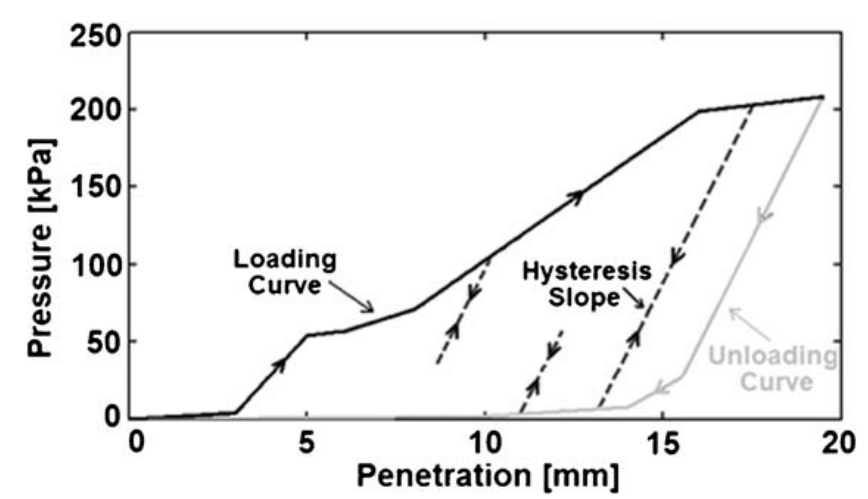

Fig. 7 The contact pressure function

penetrate into the rigid-seat surfaces and it employs a hysteresis model. When the penetration rate changes sign, the contact surfaces load and unload the rigid seat along the hysteresis slope until the loading and unloading curves are reached. The shape and energy-absorbing characteristics of this function are similar to those of the pendulum impact tests.

The contact forces can be formulated by defining two or more parallel lines on each rectangular contact surface. As the BMH model is designed to work only in the $x-z$ plane (see Fig. 6), these parallel lines can be selected to be vertical to the $x-z$ plane. The generation of the contact forces can be described simply by the example shown in Fig. 6 . When a contact surface penetrates into the rigid-seat back or seat pan, the pressure distribution developed on the contact surface can be approximated by using the penetrations of the top and the bottom edges denoted by $\delta_{\mathrm{T}}$ and $\delta_{\mathrm{B}}$ respectively. $\delta_{\mathrm{T}}$ and $\delta_{\mathrm{B}}$ lead to the pressures $P_{\mathrm{T}}$ and $P_{\mathrm{B}}$ as defined by the function in Fig. 7. The pressure distribution as defined by $P_{\mathrm{T}}$ and $P_{\mathrm{B}}$ produces a resultant normal force $\Sigma N$, a resultant moment $\Sigma \boldsymbol{M}$, and a resultant frictional force $\Sigma \boldsymbol{F}_{\mathrm{f}}$ which can be expressed at the geometrical centre of each contact surface. In cases where one of the edges of the contact surface is not in contact with the seat surface, the contact algorithm finds the edge that forms the intersection between the seat and contact surface and, then, the pressure is distributed accordingly. The simulations revealed that modelling the contact forces as such provides more realistic interaction, and hence better prediction of JARI volunteer responses in comparison with using the default contact model of VisualNastran.

The linear stiffness and damping properties of the thoracic and lumbar spine model given by van den Kroonenberg et al. [10] were utilized to make the initial estimates for the mechanical properties of the four torso joints of the BMH model. Linear stiffness

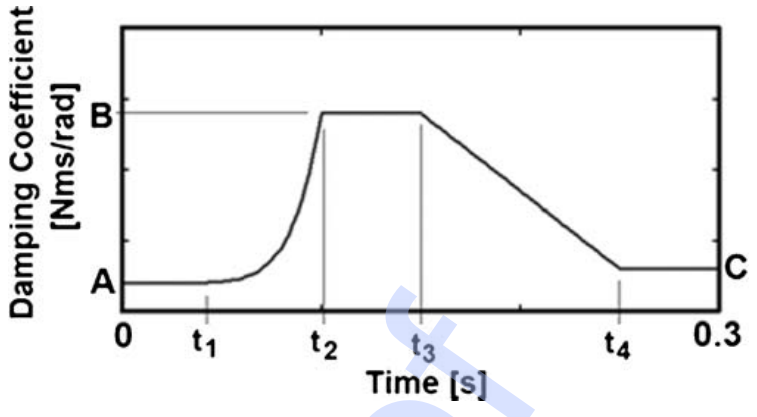

Fig. 8 Time-varying damping coefficients

and damping values resulted in satisfactory responses up to $100 \mathrm{~ms}$. However, from then on, similar to the method which was previously applied to the head-and-neck section of the BMH model [4], variable damping coefficients were required to accompany the linear stiffness functions to obtain better responses. As shown in Fig. 8, the timevarying damping coefficient functions were constructed by tuning the values of the parameters $A, B$, $C$, and $t_{1}$ to $t_{4}$. The variations in the damping coefficients are in fact similar to the muscle EMG response patterns recorded in rear-impact experiments $[6,31-33]$. In the human body, there are different muscle groups with different attachment points, which can produce different EMG responses. Therefore, the variations in joint stiffness and damping functions which were mathematically determined through validation also have physical significance with regard to mimicking the muscle activity and the increase in the resistance of the human body under dynamic conditions. The final set of torso-joint stiffness and damping functions is presented in Fig. 9. After the initial linear stiffness region, the torso-joint static torques were increased using higher stiffness values in accordance with the volunteer responses. This represents a non-linear increase in the torques as the equivalent ROMs are reached. Similar types of stiffness functions with the same order of magnitude were used for the spine joints in the BioRID design $[\mathbf{1 2}, \mathbf{1 3}]$.

The ROMs for each of the neck joints of the BMH model are $12.5^{\circ}$ in extension and $6^{\circ}$ in flexion. Thus, mathematically, for the eight neck joints, the total extension and flexion ROMs of the neck become $100^{\circ}$ and $48^{\circ}$ respectively. This is in agreement with the reported ROM values for young healthy males and the corresponding human-body models $[\mathbf{1 3}, \mathbf{3 4}, \mathbf{3 5}]$. In constructing the joint end limits for the neck joints, the static torque values were increased steeply after $150 \mathrm{Nm}$ similar to the neck-joint stiffness function variation of the computational BioRID 

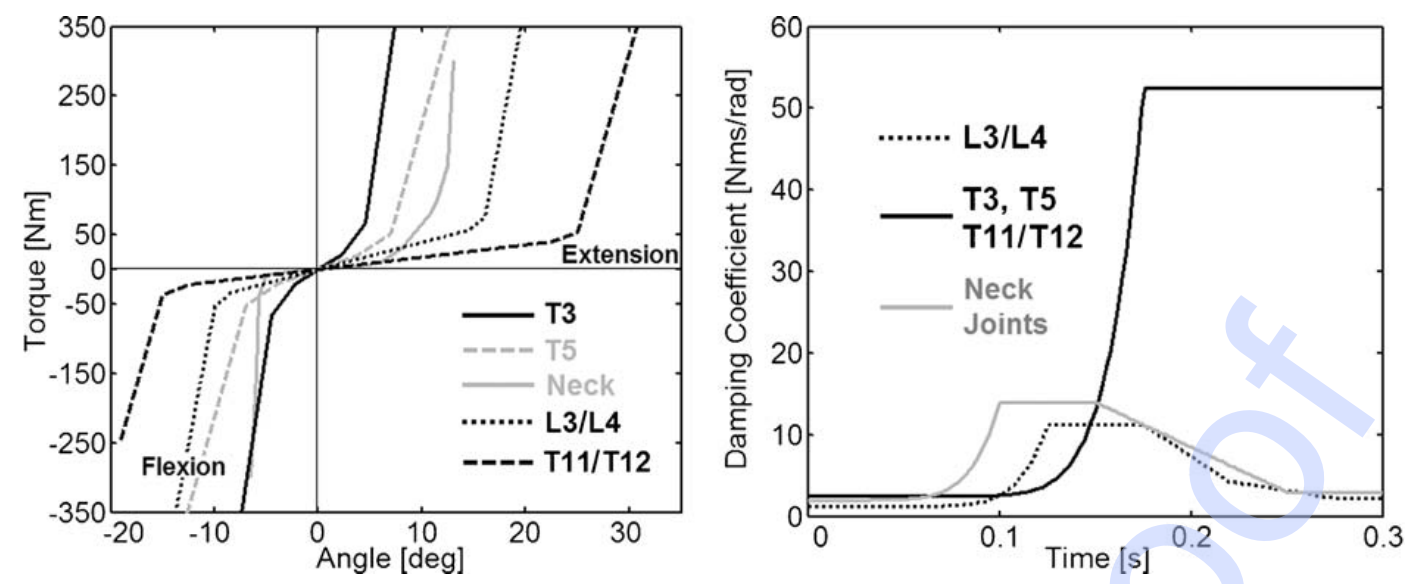

Fig. 9 Stiffness and damping functions of the BMH model torso joints

model [12]. The BMH model was subjected to highseverity rear-impact pulses up to $\Delta V=35 \mathrm{~km} / \mathrm{h}$ to ensure that the stiffness functions do not bottom out in simulating high-injury-risk scenarios.

\section{EVALUATION OF THE BMH MODEL RESPONSES}

The responses of the BMH model have been compared with the responses of the JARI volunteers and the BioRID P3 dummy which was also subjected to the same JARI rear-impact rigid-seat sled tests as described in section 2 . Three coordinate systems, as shown in Fig. 10, are attached to the head and upper torso to display the responses. The trajectory and the rotation of $\mathrm{T} 1$ are displayed relative to the sled and expressed in the inertial coordinate system shown in Fig. 5. T1 accelerations are expressed in the coordinate system attached to the $\mathrm{Tl}$ accelerometer

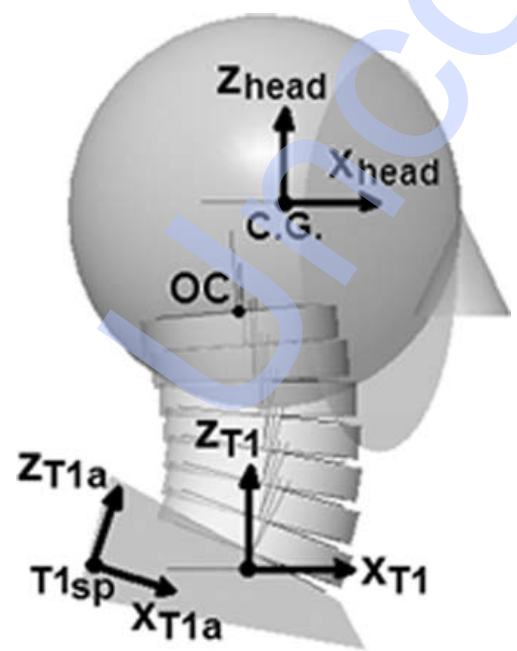

Fig. 10 Head and upper-torso coordinate systems centred on the $\mathrm{T} 1$ spinous process $\left(\mathrm{T} 1_{\mathrm{sp}}\right)$. The head angle is displayed both with respect to both the sled and T1. OCs with respect to T1 displacements are expressed in the $\mathrm{T} 1$ anatomical coordinate system [4] attached to T1. Head accelerations are expressed in the head coordinate system located at the head CG. The IC trajectory is displayed relative to the sled and the spine elongation is defined as the change of distance between IC and T1.

The responses together with the biofidelity corridors established by calculating the mean response \pm one standard deviation of the JARI volunteer response data are presented in Figs 11 to 13. The majority of the BioRID P3 responses have been given in reference [17] and are denoted by BioRID P3 $3_{(1)}$. The remaining BioRID P3 responses have been provided in reference [36] and are denoted by BioRID II P3 $3_{(2)}$. The complete set of volunteer responses have been given in reference $[\mathbf{2 8}]$ and are shown by the grey curves with the exception that both the T1 accelerations and the IC responses (Fig. 13) of the volunteers are available only in terms of the biofidelity corridors and these were obtained from reference [17]. The motion of the BMH model is illustrated in Fig. 14. The maximum head retraction relative to the upper torso (also defined as the most prominent S-shape) occurs at $89 \mathrm{~ms}$.

The responses indicate that, when the separately validated biofidelic head-and-neck model, as reported by Himmetoglu et al. [4], is integrated into the torso, the $\mathrm{BMH}$ model can predict $\mathrm{T} 1$ responses with a good level of accuracy. The BMH model also simulates spine elongation and straightening effects successfully as indicated by the $z$ displacements of $\mathrm{T} 1$ and IC. Overall, the BMH model responses show very good agreement with the volunteer data especially within the first $200 \mathrm{~ms}$ of the impact during which contact between the head and the 

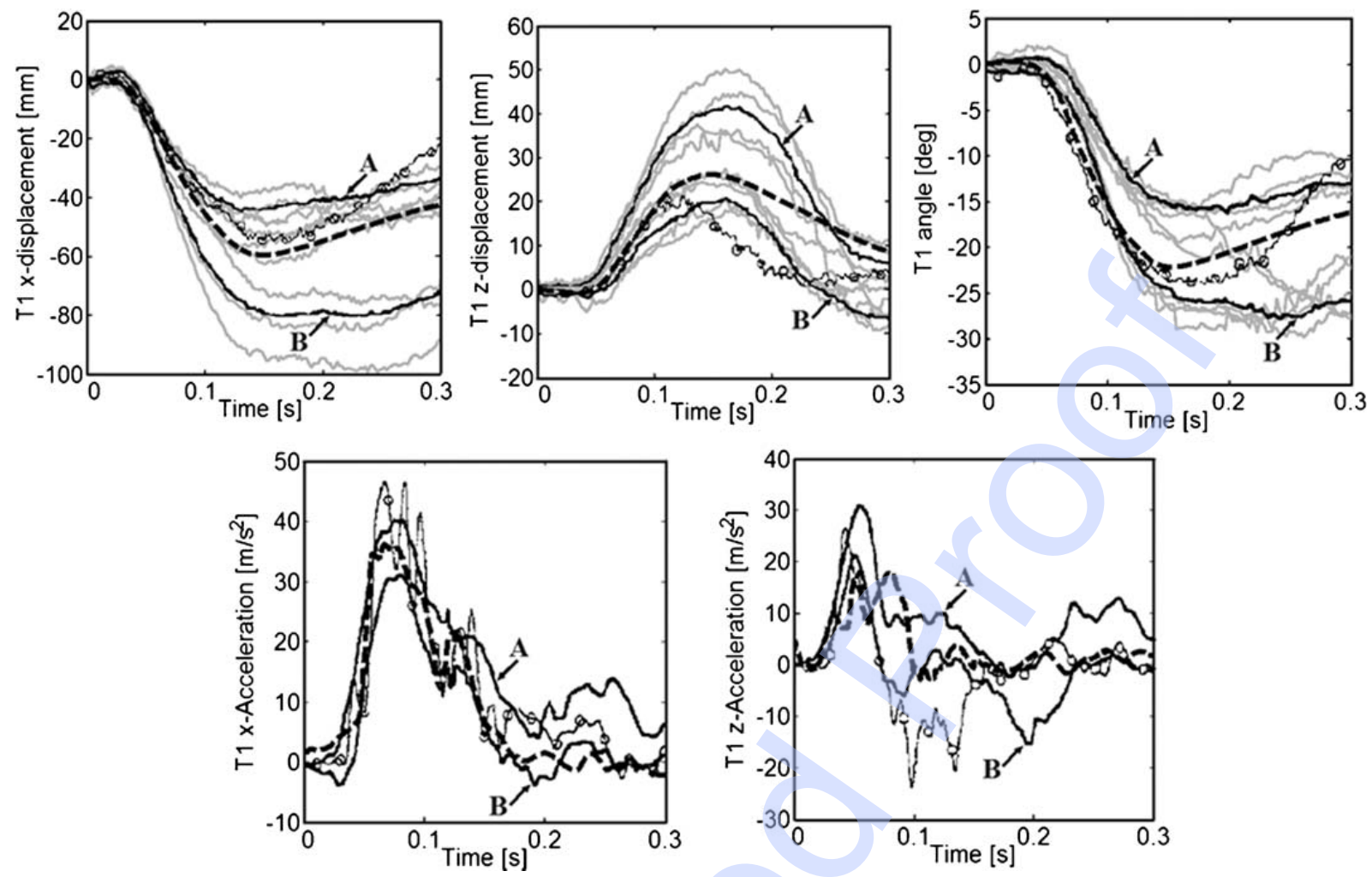

Fig. 11 T1 responses: grey curves, volunteers; curves $\mathrm{A}$ and $\mathrm{B}$, volunteer mean $\pm \mathrm{SD}$; - - $\mathrm{BMH}$ model; —o-, BioRID P3 $(1)$
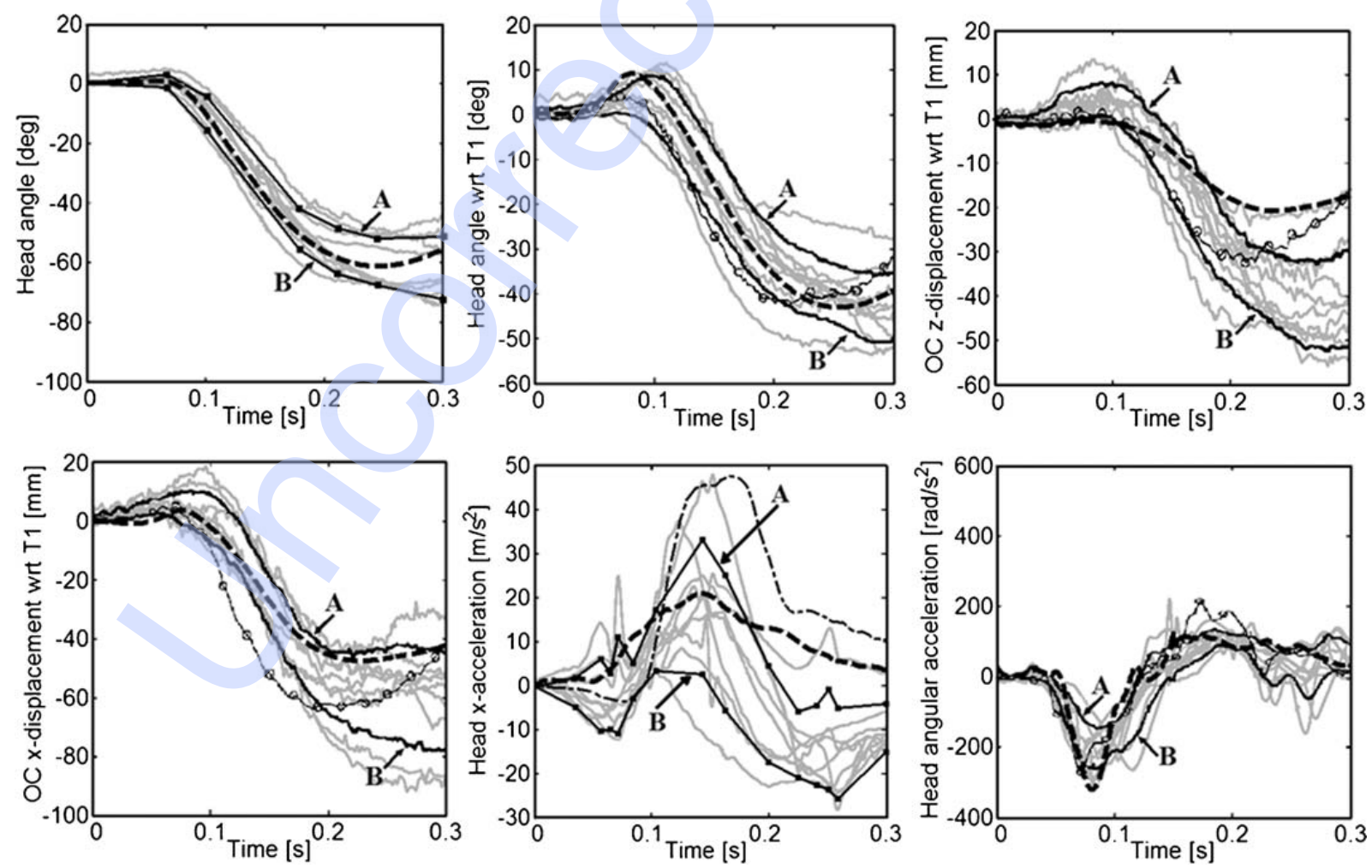

Fig. 12 Head responses: grey curves, volunteers; curves $A$ and $B$, volunteer mean $\pm \mathrm{SD}$; - BMH model; —o-, BioRID P3 $(1) ;-\bullet-$ BioRID P3 $_{(2)}$ 

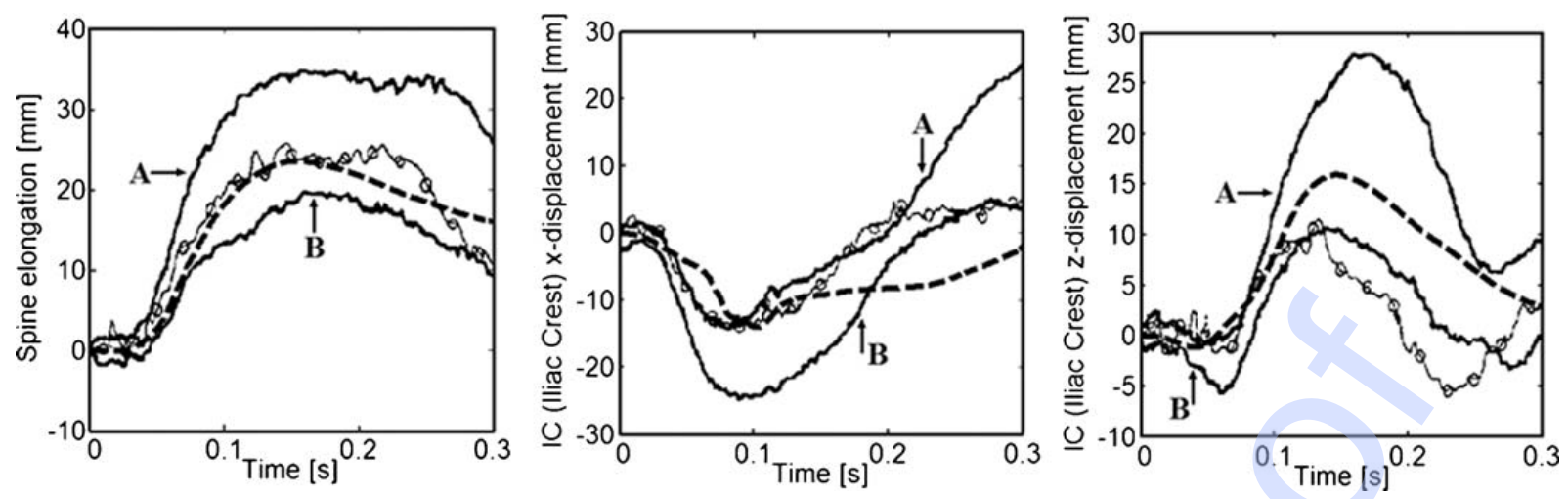

Fig. 13 IC displacements and spine elongation: curves A and B, volunteer mean $\pm \mathrm{SD},-\mathbf{-}$ BMH model; -0-, BioRID P3 $(1)$

head restraint has already been completed in a typical rear-end car collision. Moreover, the BMH model reponses are generally more biofidelic than that of the BioRID which is the most biofidelic rearimpact dummy to date. The BMH model also performs better than Hybrid III and the TNO model (i.e. the human-body model of TNO with a detailed head-and-neck model [28]) whose responses to the same JARI impact conditions can be found in reference [4].

Figures 11 to 13 have shown the biofidelity of the BMH model with regard to the volunteer responses presented by Davidsson et al. [17]. Additionally, the torso rotations of the BMH model (Fig. 15(a)) have been compared with the spine deformation of one representative volunteer (Fig. 1) given by Ono et al. [18]. As shown in Table 4, the vertebra groups of the representative volunteer are denoted by $\mathrm{TS} i^{*}(i=$ $1, \ldots, 5)$ which in fact correspond to the torso segments TSi $(i=1, \ldots, 5)$ of the BMH model. Table 4 also compares the largest rotations attained by the torso segments TSi of the BMH model with that of the representative volunteer $\mathrm{TS} i^{*}$. The largest rotation of each $\mathrm{TS}^{*}$ is obtained by averaging the largest rotations of the individual vertebrae within a group. When Fig. 15(a) is compared with Fig. 1, it can be seen that the TSi rotations of the BMH model are generally higher than the $\mathrm{TS} i^{*}$ rotations of the representative volunteer. The response patterns of TS1, TS2, and TS4 are in agreement with that of the representative volunteer vertebra groups (i.e. TS1*, TS2*, and TS4* respectively) but, for TS3 and TS5, there are some differences. However, Fig. 15(b) indicates that the $\mathrm{T} 1$ rotation of the representative volunteer, given by Ono et al. [18], is not representative of the $\mathrm{T} 1$ rotations of the volunteers (shown by the grey curves) given by Davidsson et al. [17] and it is also outside the biofidelity corridors (shown by curves $\mathrm{A}$ and $\mathrm{B}$ ) in the latter half of the impact. (In analysing the figures, it must be noted that the Davidsson et al. [17] and Ono et al. [18] used opposite sign conventions for sagittal rotations). In

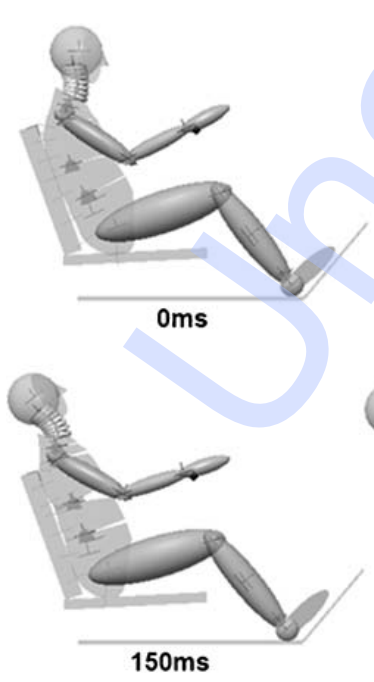

$150 \mathrm{~ms}$
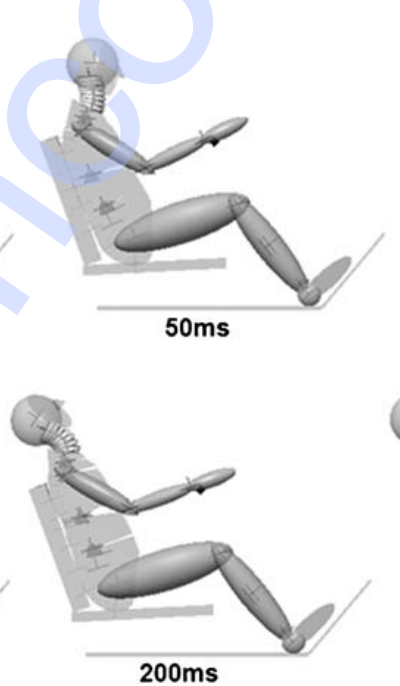
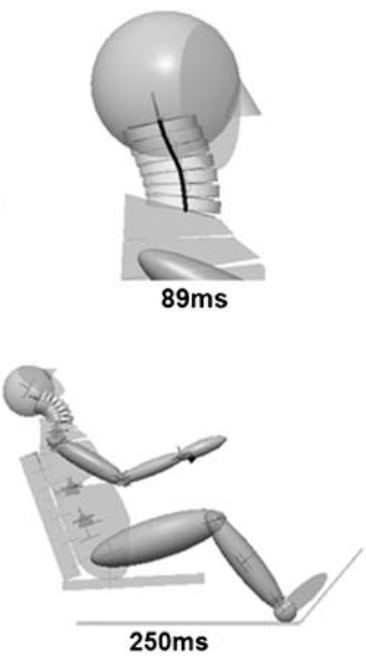

$250 \mathrm{~ms}$
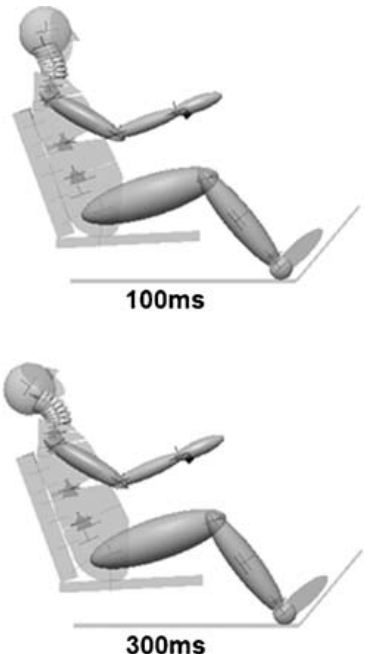

Fig. 14 Motion of the BMH model 


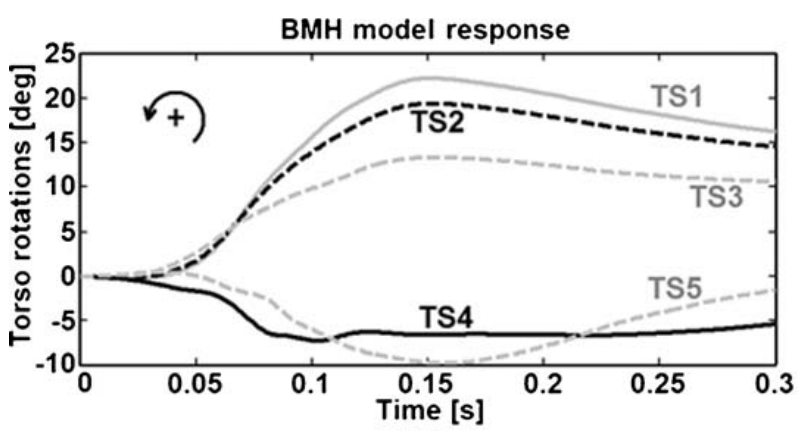

(a)

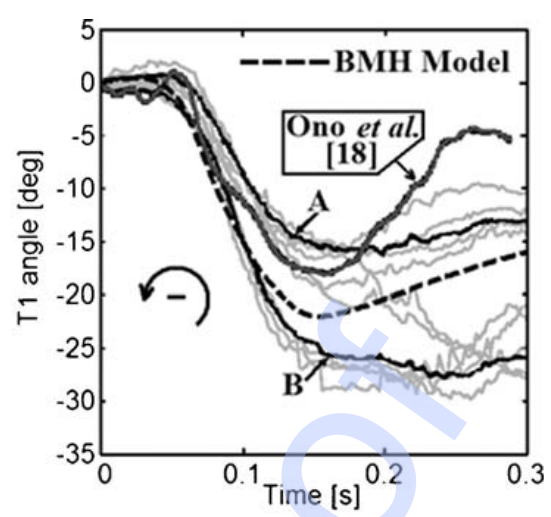

(b)

Fig. 15 (a) Torso-segment rotations of the BMH model; (b) T1 rotation of the volunteers. Anticlockwise rotations are defined $(+)$ in $(\mathrm{a})$, but $(-)$ in (b)

fact, the T1 (or TS1) rotations of the BMH model better represent the $\mathrm{T} 1$ rotations of the volunteers (shown by the grey curves); hence it should be reasonable to obtain larger rotations for TS1, TS2, and TS3 in the BMH model.

TS4 simulates the rotation of the upper lumbar region successfully, but the lower lumbar and pelvis rotations represented by TS5 are larger than those of the representative volunteer. The IC displacements are indicative of pelvis motion relative to the seat back and, as shown in Fig. 13, the IC $x$ displacements of both the BMH model and BioRID P3 are very similar up to $175 \mathrm{~ms}$ after which the pelvis loses contact with the seat back. Thus, the BMH model predicts pelvis loading reasonably well. It should be noted that, in the BioRID P3 validation tests [17], a thick $25 \mathrm{~mm}$ padding was attached to the back of the pelvis to achieve the IC responses shown in Fig. 13. Although the BMH model do not fully represent the lower lumbar and pelvis motion, it is a model with the simplest architecture which successfully satisfies the rear-impact dummy biofidelity evaluation criteria [37] based on the head and upper-torso responses of the JARI volunteers recorded by Davidsson et al. [17].

Considering the largest rotations at the torso joints of the BMH model in response to the JARI impact

Table 4 The largest torso-segment rotations

\begin{tabular}{|c|c|c|c|}
\hline \multicolumn{2}{|c|}{ BMH model } & \multicolumn{2}{|c|}{$\begin{array}{l}\text { Representative volunteer } \\
\text { (see Fig. 1) }\end{array}$} \\
\hline $\begin{array}{l}\text { Torso } \\
\text { segment }\end{array}$ & $\begin{array}{l}\text { Largest rotation } \\
\text { (deg) }\end{array}$ & $\begin{array}{l}\text { Torso } \\
\text { segment }\end{array}$ & $\begin{array}{l}\text { Largest rotation } \\
\text { (deg) }\end{array}$ \\
\hline TS1 & 22.3 & TS1* & 17 \\
\hline TS2 & 19.4 & TS2* & 13 \\
\hline TS3 & 13 & TS3* & 5 \\
\hline TS4 & -7.3 & TS4* & -9 \\
\hline TS5 & -9.7 & TS5* & -4 \\
\hline
\end{tabular}

conditions, the average stiffness values of the BMH model torso joints which can be obtained from Fig. 9, are compared with the linear torso-joint stiffnesses of the Bourdet-Willinger [15] model in Table 5. It can be seen that the torso-joint stiffnesses of the BMH model within the equivalent ROMs (i.e. before the slopes rise steeply in the stiffness function) agree quite well with that of the BourdetWillinger model which were determined using modal analysis. In the BMH model, there is one more joint at the upper torso (i.e. T3), whereas the Bourdet-Willinger model has one more joint in the lower torso at S2 but with a high stiffness value. However, in the Bourdet-Willinger model, constant damping coefficients (ranging from $0.1 \mathrm{~N} \mathrm{~m} \mathrm{~s} / \mathrm{rad}$ to $0.9 \mathrm{~N} \mathrm{~m} \mathrm{~s} / \mathrm{rad}$ ) were used for the torso joints without any validation against the rear-impact response of volunteers.

\section{CONCLUSIONS}

The BMH model was validated comprehensively using head, T1, and torso responses of volunteers. The BMH model response is more biofidelic than that of the currently used models and dummies. A satisfactory level of precision was achieved by developing a model with the simplest architecture

Table 5 Torso-joint stiffness values

\begin{tabular}{|c|c|c|c|}
\hline \multicolumn{2}{|c|}{ BMH model } & \multicolumn{2}{|c|}{ Bourdet-Willinger [15] model } \\
\hline $\begin{array}{l}\text { Torso } \\
\text { joint }\end{array}$ & $\begin{array}{l}\text { Stiffness } \\
\text { (N m/rad) }\end{array}$ & $\begin{array}{l}\text { Torso } \\
\text { joint }\end{array}$ & $\begin{array}{l}\text { Stiffress } \\
\text { (N m/rad) }\end{array}$ \\
\hline T3 & 565 & T6 & 625 \\
\hline T5 & 430 & T12 & 92 \\
\hline T11-T12 & 100 & L3 & 224 \\
\hline L3-L4 & 225 & $\mathrm{~S} 2$ & 643 \\
\hline
\end{tabular}


possible and introducing a practical method to imitate muscle activity. The stiffness properties were extended by defining equivalent ROMs, which enables the BMH model to be used in higher-severity rear-impact scenarios. The BMH model can therefore be used as a supplementary and economical tool to investigate the feasibility of seat and head restraint designs before proceeding to more complex models and/or crash testing with the BioRID dummy.

\section{REFERENCES}

1 Avery, M., Giblen, E., Weekes, A., and Zuby, D. S. Developments in dynamic whiplash assessment procedures. In Proceedings of the International Conference on Neck Injuries in Road Traffic and Prevention Strategies, Munich, Germany, 5-6 November 2007, paper 15.

2 Eis, V., Fay, P., and Sferco, R. A detailed analysis of the characteristics of European rear impacts. In Proceedings of the 19th International Technical Conference on Enhanced Safety of Vehicles, Washington, DC, USA, 6-9 June 2005, paper 050385-O (National Highway Traffic Safety Administration, Washington, DC).

3 Edwards, M., Smith, S., Zuby, D. S., and Lund, A. K. Improved seat and head restraint evaluations. In Proceedings of the 19th International Technical Conference on Enhanced Safety of Vehicles, Washington, DC, USA, 6-9 June 2005, paper 050374-O (National Highway Traffic Safety Administration, Washington, DC).

4 Himmetoglu, S., Acar, M., Taylor, A. J., and Bouazza-Marouf, K. A multi-body head-and-neck model for simulation of rear impact in cars. Proc. IMechE, Part D: J. Automobile Engineering, 2007, 221 (5), 527-541.

5 Wismans, J., Happee, R., and van Dommelen, J. A. W. Computational human body models. In Proceedings of IUTAM Symposium on Impact Biomechanics: From Fundamental Insights to Applications, Dublin, Ireland, 2005, pp. 417-429.

6 Kingma, H., Patijn, J., de Jong, I., Gosens, H. W., Stevens, J., Dekker, A., Lansbergen, M., van der Horst, M., Wismans, J., and van Mameren, $\mathbf{H}$. Impact of muscle contraction upon head stabilisation during sudden forward acceleration. Report, Maastricht University, Maastricht, The Netherlands, 2002.

7 van Lopik, D. W. and Acar, M. Dynamic verification of a multi-body computational model of human head and neck for frontal, lateral, and rear impacts. Proc. IMechE, Part K: J. Multi-body Dynamics, 2007, 221(2), 199-217.

8 Zhang, Q. H., Tan, S. H., and Teo, E. C. Finite element analysis of head-neck kinematics under simulated rear impact at different accelerations.
Proc. IMechE, Part H: J. Engineering in Medicine, 2008, 222(5), 781-790.

9 Jakobsson, L., Norin, H., Jernström, C., Svensson, S.-E., Johnsen, P., Isaksson-Hellman, I., and Svensson, M. Y. Analysis of different head and neck responses in rear-end car collisions using a new humanlike mathematical model. In Proceedings of the International IRCOBI Conference, Lyon, France, 1994, pp. 109-125 (International Research Council on Biomechanics of Injury, Zurich).

10 van den Kroonenberg, A., Thunnissen, J., and Wismans, J. A human model for low-severity rearimpacts. In Proceedings of the International IRCOBI Conference, Hannover, Germany, 1997, pp. 117-132 (International Research Council on Biomechanics of Injury, Zurich).

11 Schneider, L. W., Robbins, D. H., Pflueg, M. A., and Snyder, R. G. Development of anthropometrically based design specifications for an advanced adult anthropomorphic dummy family Vol. 1. Report UMTRI-83-53-1, Transportation Research Institute, University of Michigan, Ann Arbor, Michigan, USA, 1983.

12 Eriksson, L. Three-dimensional mathematical models of the BioRID I and car seats for low-speed rear-end impacts. Traffic Injury Prev., 2002, 3(1), 75-87.

13 Davidsson, J., Svensson, M. Y., Flogård, A., Håland, Y., Jakobsson, L., Linder, A., Lövsund, P., and Wiklund, K. BioRID I - a new biofidelic rear impact dummy. In Proceedings of the International IRCOBI Conference, Göteborg, Sweden, 1998, pp. 377-390 (International Research Council on Biomechanics of Injury, Zurich).

14 Willinger, R., Bourdet, N., Fischer, R., and Le Gall, F. New method for biofidelity evaluation of dummy necks. In Proceedings of the 18th International Technical Conference on Enhanced Safety of Vehicles, Nagoya, Japan, 19-22 May 2003, paper 343, (National Highway Traffic Safety Administration, Washington, DC).

15 Bourdet, N. and Willinger, R. Modeling of car seat and human body interaction under rear impact. Int. J. Crashworthiness, 2006, 11(6), 553-560.

16 Kitazaki, S. and Griffin, M. J. Resonance behaviour of the seated human body and effects of posture. $J$. Biomechanics, 1998, 31(2), 143-149.

17 Davidsson, J., Ono, K., Inami, S., Svensson, M. Y., and Lövsund, P. A comparison between volunteer, BioRID P3 and Hybrid III performance in rear impacts. In Proceedings of the International IRCOBI Conference, 1999, Sitges, Spain, 1999, pp. 165-178 (International Research Council on Biomechanics of Injury, Zurich).

18 Ono, K., Inami, S., Kaneoka, K., Gotou, T., Kisanuki, Y., Sakuma, S., and Miki, K. Relationship between localized spine deformation and cervical vertebral motions for low speed rear impacts using human volunteers. In Proceedings of the International IRCOBI Conference, Sitges, 
Spain, 1999, pp. 149-164 (International Research Council on Biomechanics of Injury, Zurich).

19 Jernström, C., Nilson, G., and Svensson, M. Y. A first approach to an implementation in MADYMO of a human body model for rear-impact modelling. In Procedings of the Fourth International MADYMO Users' Meeting, Eindhoven, The Netherlands, 6-7 September 1993.

20 Chaffin, D. B. and Andersson, G. B. J. Occupational biomechanics, 2nd edition, 1991 (John Wiley, New York).

21 Robbins, D. H. Anthropometric specifications for mid-sized male dummy, Vol. 2. Report UMTRI-8353-2/UMTRI-83-53-3, Transportation Research Institute, University of Michigan, Ann Arbor, Michigan, USA, 1983.

22 Robbins, D. H. Anthropometric specifications for small female and large male dummies, Vol. 3. Report UMTRI-83-53-3, Transportation Research Institute, University of Michigan, Ann Arbor, Michigan, USA, 1983.

23 Happee, R., Ridella, S., Nayef, A., Morsink, P., de Lange, R., Bours, R., and van Hoof, J. Mathematical human body models representing a mid-size male and a small female for frontal, lateral and rearward impact loading. In Proceedings of the International IRCOBI Conference, Montpellier, France, 2000, pp. 67-81 (International Research Council on Biomechanics of Injury, Zurich).

24 Engin, A. E. On the damping properties of the shoulder complex. J. Biomech. Engng, 1984, 106(4), 360-363.

25 Tafazzoli, F. and Lamontagne, M. Mechanical behaviour of hamstring muscles in low-back pain patients and control subjects. Clin. Biomechanics, 1996, $11(1), 16-24$.

26 Hayes, K. C. and Hatze, H. Passive visco-elastic properties of the structures spanning the human elbow joint. Eur. J. Appl. Physiology, 1977, 37(4), 265-274.

27 McFaull, S. R. and Lamontagne, M. In vivo measurement of the passive viscoelastic properties of the human knee joint. Human Movement Sci., 1998, 17(2), 139-165.

28 van der Horst, M. J. Human head neck response in frontal, lateral and rear end impact loading: modelling and validation, $\mathrm{PhD}$ Thesis, Eindhoven University of Technology, Eindhoven, The Netherlands, 2002.

29 VisualNastran 4D Manual, 2001 (MSC Software, Santa Ana, California).

30 Viano, D. C., Hardy, W. N., and King, A. I. Response of the head, neck and torso to pendulum impacts on the back. Crash Prev. Injury Control, 2001, 2(4), 289-306.

31 Szabo, T. J. and Welcher, J. B. Human subject kinematics and electromyographic activity during low speed rear impacts. SAE paper 962432, 1996.

32 Magnusson, M. L., Pope, M. H., Hasselquist, L., Bolte, K. M., Ross, M., Goel, V. K., Lee, J. S., Spratt, K., Clark, C. R., and Wilder, D. G. Cervical electromyographic activity during low-speed rear impact. Eur. Spine J., 1999, 8(2), 118-125.

33 Brault, J. R., Siegmund, G. P., and Wheeler, J. B. Cervical muscle response during whiplash: evidence of a lengthening muscle contraction. Clin. Biomechanics, 2000, 15(6), 426-435.

34 Foust, D. R., Chaffin, D. B., Snyder, R. G., and Baum, J. K. Cervical range of motion and dynamic response and strength of cervical muscles. SAE paper 730975, 1973.

35 Linder, A. A new mathematical neck model for a low-velocity rear-end impact dummy: evaluation of components influencing head kinematics. Accid. Analysis Prev., 2000, 32(2), 261-269.

36 Viano, D. C. and Davidsson, J. Neck displacements of volunteers, BioRID P3 and Hybrid III in rear impacts: implications to whiplash assessment by a neck displacement criterion (NDC). Traffic Injury Preve., 2002, 3(2), 105-116.

37 Wismans, J. Results of the EEVC whiplash dummy comparison programme. In Proceedings of the International Conference on Neck Injuries in Road Traffic and Prevention Strategies, Munich, Germany, 5-6 November 2007, paper 22.

\section{APPENDIX}

\section{Notation}

BioRID

BioRID I

BioRID II

$\mathrm{BMH}$

CG

C1, C7

EMG

Hybrid III

IC

JARI

$\mathrm{L} i$

MADYMO

biofidelic rear-impact dummy biofidelic rear-impact dummy I commercial version of BioRID P3 biofidelic multi-body human centre of gravity first and seventh cervical vertebrae respectively electromyography frontal crash test dummy iliocristale (representing the iliac crest) Japanese Automobile Research Institute $i$ th vertebra $(i=1, \ldots, 5)$

OC occipital condyle

$P_{\mathrm{B}}, P_{\mathrm{T}} \quad$ pressures at the bottom and top edges respectively of the torso contact surface

ROM range of motion

Si sacral element $i(i=1, \ldots, 8)$

$\mathrm{T} i \quad i$ th thoracic vertebra $(i=1, \ldots, 12)$

TNO TNO Automotive, Crash Safety Centre, Helmond, The Netherlands

TS $i \quad i$ th torso segment $(i=1, \ldots, 5)$

$\mathrm{T} 1_{\mathrm{sp}} \quad \mathrm{T} 1$ spinous process 


$\begin{array}{llll}\text { UMTRI } & \begin{array}{l}\text { University of Michigan } \\ \text { Transportation Research Institute }\end{array} & \Delta V & \begin{array}{l}\text { change in the velocity of a vehicle } \\ \text { subjected to a crash pulse }\end{array} \\ \delta_{\mathrm{B}}, \delta_{\mathrm{T}} & \begin{array}{l}\text { penetrations of the bottom and top } \\ \text { edges respectively of the torso } \\ \text { contact surface }\end{array} & \begin{array}{l}\text { resultant normal force, resultant } \\ \text { moment and, resultant frictional } \\ \text { force respectively on the torso } \\ \text { contact surface }\end{array}\end{array}$

